\title{
Global warming and world soybean yields
}

\author{
CAI CHENG-ZHI ${ }^{*}$, LIAO CONG-JIAN ${ }^{1}$, XIAO DAN ${ }^{2}$, ZENG XIAO-SHAN ${ }^{3}$ and ZUO JIN \\ ${ }^{1}$ Economic Institute, Guizhou University of Finance and Economics, Guiyang \\ ${ }^{2}$ Economic System Simulation Lab, Guizhou University of Finance and Economics, Guiyang \\ ${ }^{3}$ Guizhou Provincial Institute of Mountain Environment and Climate, Guiyang, China \\ "Ccorresponding author email : caichengzhi@mail.gufe.edu.cn
}

\begin{abstract}
The crop yield potential of world soybean from 2019 to 2028 has been projected using ARIMA model based on the yields from 1961 to 2018. Both annual global mean temperature and the yields of world soybean have been projected to rise during the ensuing decade 2019-2028. Projected average yields of world soybean varies from 2841 to $3276 \mathrm{~kg} \mathrm{ha}^{-1}$ while 4324 to $4807 \mathrm{~kg} \mathrm{ha}^{-1}$ in the case of top (national) yields of world soybean. Annual global mean temperatures may vary from 15.0 to $15.3^{\circ} \mathrm{C}$ and likely to exert positive impact on average yield $(\mathrm{R}$ squared $=0.80)$ while negative on top yield ( $\mathrm{R}$ squared $=0.40$ ) of world soybean. It may be concluded that for world soybean yields in 2019 to 2028, the opportunities for improving production should be dependent on both high and low-yielding countries as the yield remained between 30 and 70 per cent of potential limit i.e. in middle place around the turn-point of $S$-shaped curve in long-term trend partly affected by global warming.
\end{abstract}

Key words: World soybean, yield potential, ARIMA model, global warming.

Soybean crop has been attracting academic attention for improving its potential yield in the future particularly under climate change. The regression models constructed for estimating the yield of soybean in Far Eastern Federal District (FEFD) of Russia, which showed the soybean yield forecast for 2018 having a deviation from the actual yield in the range of 2.1-7.3 per cent based on 2007-2017 data (Stepanov et al., 2019). Using the AquaCrop model, Tovjanin et al., (2019) estimated the impact of climate change on main field crops (maize and soybean) in the Republic of Serbia, and found an increase in maize ( 1 and $1.3 \mathrm{t} \mathrm{ha}^{-1}$ ) and soybean (1.9 and $2.8 \mathrm{t} / \mathrm{ha}$ ) yields for the 2041-2070 and 2071-2100 periods. Fuzzo et al., (2020) proposed a new method for predicting soybean yield in Parana state of Brazil for 2002-2003 to 2011-2012, and got the RMSE value ranging from 30.8 to $57.2 \mathrm{~kg} \mathrm{ha}^{-1}$. Historical series (2000-2019) of climate and soybean yield data in Mato Grosso do Sul state of Brazil was used for multiple linear regression modelling, which showed that the climate variable with the greatest negative influence on soybean yield $(\mathrm{r}=-0.54)$ was due to water stress in December (Aparecido et al., 2020) month. Citing the soil water balance modeled, Petry et al. (2020) investigated the crop coefficients, grain yield prediction, and economic return of soybean grown in Brazil at different levels of water deficit and price quotations, and found that crop yield and economic return were higher at 75 per cent of total available water (TAW) than the others. Using a mathematical model, Rebilas et al. (2020) estimated the dependence of seed yield losses upon cutting height variations, and found that all were below $15 \mathrm{~g} / \mathrm{m}^{2}$ even for the highest cutting level $(15 \mathrm{~cm})$ applied during harvest. Walikar et al., (2018) and Singh et al. (2010) evaluated "SOYGRO" model for predicting growth and yield of soybean in Madhya Pradesh and Haryana provinces in India. There is no lack of research reports on the yield or its potential of soybean modelled and partly related to climatic factors, but most are based on the principle of production function for specific variety from static biological dimension and at local or regional level, while few based on the theory of stochastic process for generic soybean from dynamic evolutionary dimension and at global level. Thus in this paper, 'time series' model ARIMA (Autoregressive Integrated Moving Average) based on stationary stochastic process to estimate potential yield of world soybean under global warming was used 
for projecting soybean yield on its historic yields basis. It is also aimed to provide information on directing the production of soybean in the world facing global food insecurity deteriorated by the contradiction between the increase of human demand and the degradation of arable land.

\section{MATERIALS AND METHODS}

\section{Datasets used}

Annual global mean temperature $\left({ }^{\circ} \mathrm{C}\right)$, average and top (national) yields of world soybean from 1961 to 2018 are employed to project and analyze their futures facing global warming. As shown in Fig. 1, from 1961 to 2018: annual global mean temperature rose in fluctuation; average yields of world soybean rose more steadily than the top yields. 'Average yield' means average yield of soybean worldwide while 'top yield' comes from specific countries whose yield of soybean countrywide topped in the world in given year in the following. Canada enjoyed the yields of soybean countrywide being top in the world in 1961; so did Mexico in 1962, 1963 and 1965; Paraguay in 1964, 1966, 1968 and 1969; Italy in 1967, 1973, 1974, 1977, 1984, 1986, 1989 to 1999, 2001, 2002 and 2005; Ethiopia PDR in 1970, 1971, 1972, 1979, 1980, 1981,1982, 1983, 1985, and 1987, 1988, 1989; New Zealand in 1975, 1976 and 1978; Switzerland in 2000; Egypt in 2003; Turkey in 2004 and 2006 to 2018.

\section{Methodology applied}

ARIMA model is a valuable tool used for projecting the futures of 'time series' variable, in which it is assumed that if a stochastic process has some numbers of unit root it can be converted into a stationary process of autoregressive moving average after same times of differencing required for producing the stationarity of series. A simplified representation of the model is ARIMA $(p, d, q)$, where $p$ is the number of autoregressive parameters, $d$ is the order of differencing required for producing stationarity, and $q$ is the number of moving average parameters (Jensen, 1990). The order of differencing refers to the number of times that each previous observation is subtracted from each successive observation until no systematic decrease or increase in the level of the series remains as it drifts. The noise in a time series drifts up and down across time. A complete representation of ARIMA model is mathematically written as formula (1).

$$
\left[1-\sum_{i=1}^{p} \phi_{i} L^{i}\right](1-L)^{d} X_{t}=\left[1+\sum_{i=1}^{q} \theta_{i} L^{i}\right] \varepsilon_{t}
$$

In formula (1), besides $p, d$ and $q$ above explained, $t$ refers to the time unit while $L$ to the lag operator, $\phi(L)$ to stationary autoregressive operator, $\theta(L)$ to reversible moving average operator, and $d \in z$ to target variable.

The Autoregressive model represents a process in which the observation at time $t$ is a function of the previous observation $t-1$, while a Moving Average model represents a process in which an observation is a function of the previous random shock.

It is assumed that the yields of world soybean in the past, be a 'time series' variable as it generally rises over time due to continuous improvement of the inputs to its production through scientific and technical means. In other words, the rise of world soybean yield in a long run is of a stochastic process that hints some inevitable trend behind a large number of casual events. Therefore, dynamic potential yield of world soybean in the future can be estimated by 'time series' approach more suitable than any model based on production function considering various influential factors. Thus, in this investigation, ARIMA model was used for projecting the yields of world soybean in 2019 to 2028 based on the yields from 1961 to 2018 in principle limiting the number of samples projected less than 15 per cent of totality. In application, the projection of world soybean yields is undertaken following the steps: firstly, to produce logarithmic values of world soybean yields from 1961 to 2018 to eliminate heteroscedasticity, to test the stationarity of 'time series' and establish 'stationary series' through differencing if not stationary; secondly, to establish such five basic models as $\operatorname{ARMA}(1,2), \operatorname{ARMA}(1,1), \operatorname{AR}(1), \operatorname{MA}(2)$ and MA(1) to fit world soybean yields from 2009 to 2018 in principle equating the number of fitted samples to that to be projected, and compare fitted values with actual yields to evaluate the fitness; finally, to select and validate optimum basic model used for ARIMA $(p, d, q)$ modelling to project world soybean yields in 2019 to 2028. In same way, annual global mean temperature by 2028 has been projected using ARIMA model. Further, the impacts of global warming on the yields of world soybean has been analyzed using regression model. 


\section{RESULTS AND DISCUSSIONS}

\section{Projecting average yields of world soybean in 2019 to 2028}

Through testing it has been shown that logarithmic series of average yields of world soybean from 1961 to 2018 happen to be stationary with the t-statistic value of -5.573534 and critical value of -4.127338 at $1 \%$ level in the ADF unit root test. Thus, five basic models used for fitting average yields of world soybean from 2009 to 2018 are established on the basis of logarithmic yields values. Their equations are shown in the Table 1. The fitness of five basic models in Table 1 has been represented as the percentage of fitted value increased or decreased in comparison with actual yield (i.e. residual in the model), and resulted with such mean error (ME) from 2009 to 208 as $+1.81 \%$ of $\operatorname{ARMA}(1,2),+2.27 \%$ of $\operatorname{ARMA}(1,1)$, $+2.31 \%$ of $\operatorname{AR}(1),+2.93 \%$ of $\operatorname{MA}(2)$ and $+1.30 \%$ of MA(1). Therefore, MA(1) basic model with the best fitness was used for ARIMA $(0,0,1)$ modelling to project average yields of world soybean in 2019 to 2028 .

ARIMA model used for projecting average yields of world soybean in 2019 to 2028

As shown in Table 2, absolute value of inverted MA root (0.67) was below 1.00, which has shown the ARIMA $(0,0,1)$ model's is stationarity. Thus, average yields of world soybean in 2019, 2020, 2021, 2022, 2023, 2024, 2025, 2026, 2027 and 2028, projected using the ARIMA $(0,0,1)$ model, have to be $2841,2887,2933$, 2979, 3027, 3075, 3124, 3174, 3224 and $3276 \mathrm{~kg}^{-}$ ${ }^{1}$, respectively. For example to test the performance of ARIMA model, average yield of world soybean in 2018 projected using the ARIMA $(1,0,0)$ model based on the yields from 1961 to 2017 , was $2878 \mathrm{~kg} \mathrm{ha}^{-1}$ being only 3.12 per cent higher than the actual yield.

\section{Projecting top yields of world Soybean in 2019 to 2028}

Those countries that enjoyed top yields of world soybean in some given years, represent various casual events behind which an inevitable law limits average yield meeting the top yields. In this case, the variation of top yields of world soybean in long term has been deemed as stochastic process. This study does not aim here to reveal the effect of climatic factors on the growth of soybean in any specific country owning top yield in the world, but to explore general trend of top yields of soybean on global scale. Therefore, top yields of world soybean in 2019 to 2028 have been projected using ARIMA model for projection of the yields from 1961 to 2018 .

\section{Models used for fitting top yields of world soybean from 2009 to 2018}

It has been tested that the logarithmic series of top yields of world soybean from 1961 to 2018 was stationary (in ADF unit root test t-statistic value = -5.564368 while critical value $=-4.127338$ at $1 \%$ level). Thus, five basic models used for fitting top yields of world soybean from 2009 to 2018 have been established using logarithmic values of the yields, whose equations have been shown in the table 3 . In the same way, the fitness of five basic models in Table 3 has resulted with such ME between 2009 and 2018 as $-3.08 \%$ of $\operatorname{ARMA}(1,2)$, $-1.77 \%$ of $\operatorname{ARMA}(1,1),+0.61 \%$ of $\operatorname{AR}(1),-0.23 \%$ of $\operatorname{MA}(2)$ and $-0.21 \%$ of MA(1). Therefore, MA(1) basic model having the best fitness has been used for ARIMA $(0,0,1)$ modelling to project top yields of world soybean in 2019 to 2028.

\section{ARIMA model used for projecting top yields of world soybean in 2019 to 2028}

As shown in Table 4, absolute value of inverted MA root (0.78) is below 1.00, showing stationary ARIMA $(0,0,1)$ model. Thus, top yields of world soybean in 2019, 2020, 2021, 2022, 2023, 2024, 2025, 2026, 2027 and 2028, has been projected using $\operatorname{ARIMA}(0,0,1)$ model resulting in 4324, 4375, 4427, 4479, 4532, 4586, 4640, 4695, 4751 and $4807 \mathrm{~kg} \mathrm{ha}^{-1}$, respectively. For another example, the ARIMA $(1,0,0)$ model based on top yields of world soybean from 1961 to 2017 was used for projecting the top yield in 2018 resulted with $4468 \mathrm{~kg} \mathrm{ha}^{-1}$ being statistically acceptable 4.83 per cent higher than actual one.

\section{Global warming and world soybean yields}

Theoretically, there must exist certain inherent relationship between annual global mean temperature and the yields of world soybean because temperature has been the one of essential factors for soybean crop 
Table 1: Equations of five basic models for fitting average yields of world soybean from 2009-18

\begin{tabular}{|l|l}
\hline Model & Equation \\
\hline ARMA $(1,2)$ & $\ln a v e_{t}=0.016090+0.333881 \ln a v e_{t-1}+0.666119 \ln a v e_{t-2}+\varepsilon_{t}-0.091779 \varepsilon_{t-1}-0.262051 \varepsilon_{t-2}$ \\
ARMA $(1,1)$ & $\ln a v e_{t}=0.016219+0.677099 \ln a v e_{t-1}+0.322901 \ln a v e_{t-2}+\varepsilon_{t}-0.452133 \varepsilon_{t-1}$ \\
$\operatorname{AR}(1)$ & $\ln a v e_{t}=0.016211+0.398921 \ln a v e_{t-1}+0.601079 \ln a v e_{t-2}+\varepsilon_{t}$ \\
$\operatorname{MA}(2)$ & $\ln a v e_{t}=0.016325+\varepsilon_{t}-0.763830 \varepsilon_{t-1}+0.194130 \varepsilon_{t-2}$ \\
MA $(1)$ & $\ln a v e_{t}=0.015809+\varepsilon_{t}-0.668173 \varepsilon_{t-1}$
\end{tabular}

Note: 'ave' stands for 'average yield of world soybean'

Table 2: Regression of ARIMA $(0,0,1)$ model for avg. yields of world soybean in 2019-28

\begin{tabular}{|c|c|c|c|c|}
\hline Variable & Coefficient & Std. Error & t-Statistic & Probability \\
\hline $\mathrm{C}$ & 0.015809 & 0.002370 & 6.671721 & 0.0000 \\
\hline MA(1) & -0.668173 & 0.098305 & -6.796912 & 0.0000 \\
\hline R-squared & 0.375089 & \multicolumn{2}{|c|}{ Mean dependent var } & 0.015878 \\
\hline Adjusted R-squared & 0.363727 & \multicolumn{2}{|c|}{ S.D. dependent var } & 0.064832 \\
\hline S.E. of regression & 0.051714 & \multicolumn{2}{|c|}{ Akaike info criterion } & -3.051705 \\
\hline Sum squared resid & 0.147091 & \multicolumn{2}{|c|}{ Schwarz criterion } & -2.980019 \\
\hline F-statistic & 33.01253 & \multicolumn{2}{|c|}{ Durbin-Watson stat } & 2.229911 \\
\hline Prob(F-statistic) & 0.000000 & \multicolumn{3}{|c|}{ / } \\
\hline Inverted MA Roots & 0.67 & \multicolumn{3}{|c|}{ / } \\
\hline
\end{tabular}

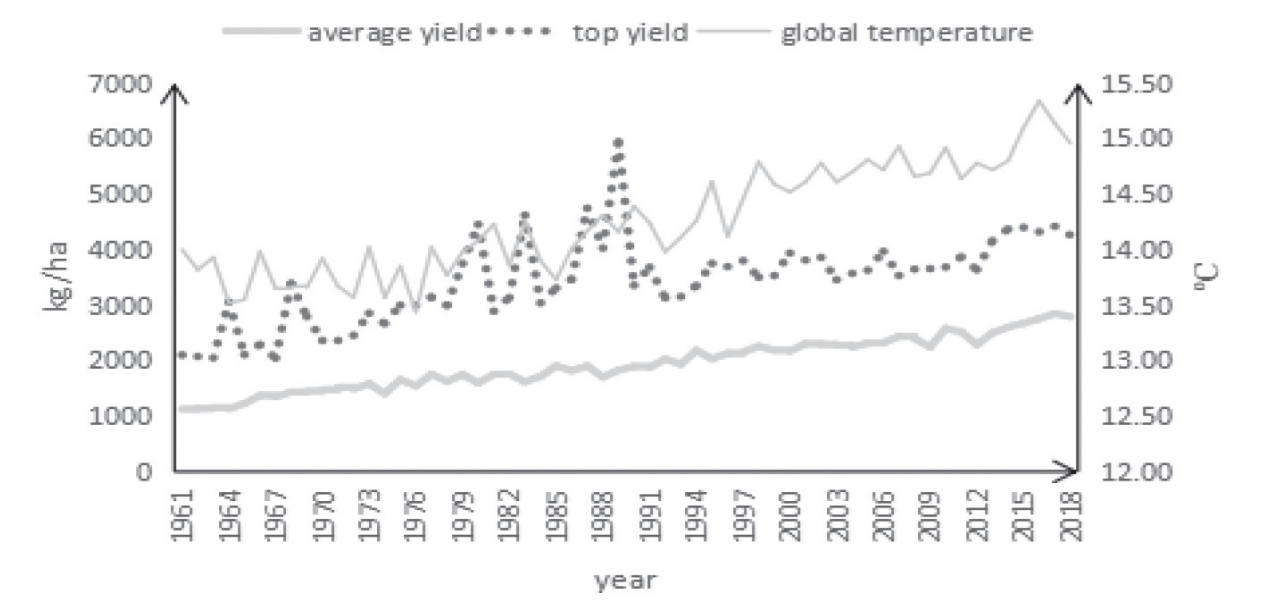

Fig. 1: Annual global mean temperature $\left({ }^{\circ} \mathrm{C}\right)$, average and top yields $\left(\mathrm{kg} \mathrm{ha}^{-1}\right)$ of world soybean from 1961 to 2018

growth and yield. Though all climatic factors viz., radiation, temperature, precipitation and gases each have their respective contribution to the growth and yield of world soybean, but only the rise of annual global mean temperature has been observed and proved to be the result of higher $\mathrm{CO}_{2}$ concentration in the atmosphere. Therefore, the contributions of solar radiation, precipitation and gases each year can be considered as constant (in modelling), to the yield of world soybean including all varieties grown in any season.

In empirical analyses, it is causality-tested that 


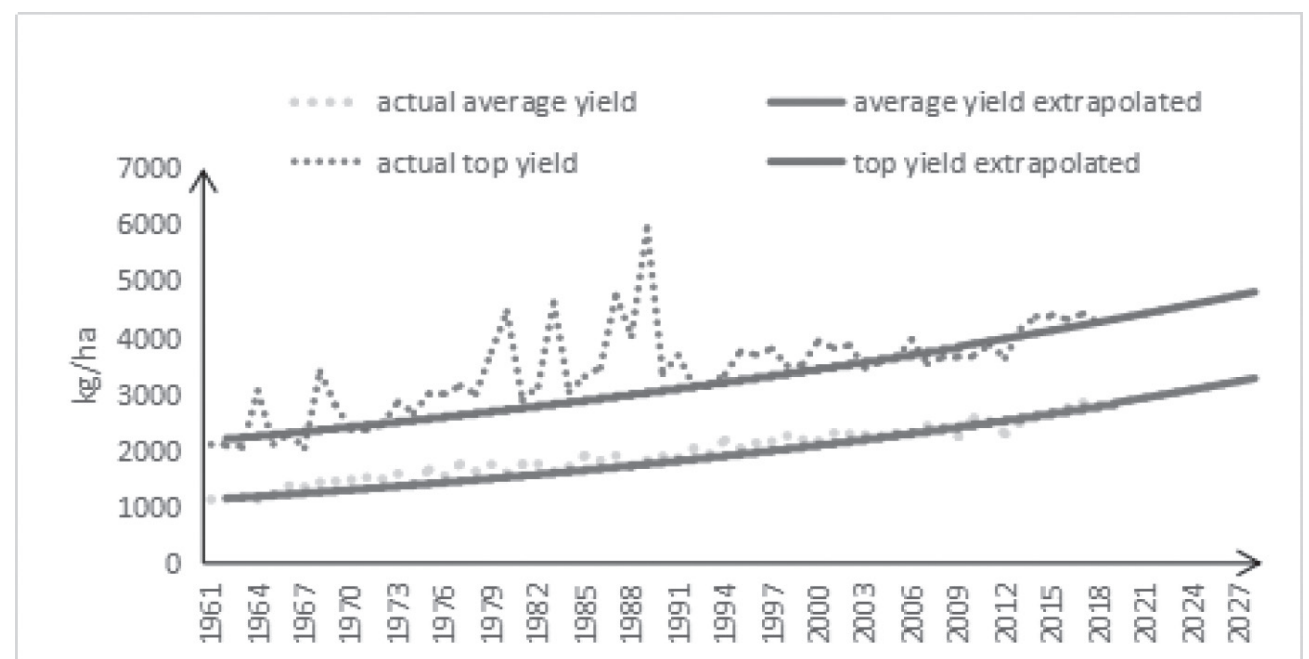

Fig. 2: Average and top yields $\left(\mathrm{kg} \mathrm{ha}^{-1}\right)$ of world soybean in 1961 to 2028

Table 3: Equations of five basic models for fitting top yields of world soybean from 2009-18

\begin{tabular}{lll}
\hline Model & Equation \\
\hline ARMA $(1,2)$ & $\ln$ top $_{t}=0.011347+0.161139 \ln$ top $_{t-1}+0.838861 \ln$ top $_{t-2}+\varepsilon_{t}+0.049902 \varepsilon_{t-1}-0.635106 \varepsilon_{t-2}$ \\
ARMA $(1,1)$ & $\ln$ top $_{t}=0.011258+1.013288 \ln$ top $_{t-1}-0.013288 \ln$ top $_{t-2}+\varepsilon_{t}-0.791336 \varepsilon_{t-1}$ \\
AR $(1)$ & $\ln$ top $_{t}=0.012984+0.506647 \ln$ top $_{t-1}+0.493353 \ln t o p_{t-2}+\varepsilon_{t}$ \\
MA (2) & $\ln$ top $_{t}=0.011770+\varepsilon_{t}-0.775882 \varepsilon_{t-1}-0.002070 \varepsilon_{t-2}$ \\
MA (1) & $\ln$ top $_{t}=0.011776+\varepsilon_{t}-0.777522 \varepsilon_{t-1}$ \\
\hline
\end{tabular}

Note: 'top' stands for 'top yield of world soybean'.

Table 4: Regression of ARIMA $(0,0,1)$ model for top yields of world soybean in $2019-28$

\begin{tabular}{lllll}
\hline Variable & Coefficient & Std. Error & t-Statistic & Probability \\
\hline C & 0.011776 & 0.004799 & 2.453848 & 0.0173 \\
MA(1) & -0.777522 & 0.082931 & -9.375541 & 0.0000 \\
R-squared & 0.375433 & Mean dependent var & 0.012393 \\
Adjusted R-squared & 0.364078 & S.D. dependent var & 0.190115 \\
S.E. of regression & 0.151607 & Akaike info criterion & -0.900592 \\
Sum squared resid & 1.264158 & Schwarz criterion & -0.828906 \\
Log likelihood & 27.66689 & Hannan-Quinn criter. & -0.872733 \\
F-statistic & 33.06105 & Durbin-Watson stat & 1.995733 \\
Prob(F-statistic) & 0.000000 & $/$ & \\
Inverted MA Roots & 0.78 & $/$ & \\
\hline
\end{tabular}

there exist Granger causalities between annual global mean temperature and average yield $(\mathrm{P}=0.0009$ while F-Statistic $=8.00150)$ and top yield $(\mathrm{P}=0.0821$ while F-Statistic $=2.62690)$ of world soybean from 1961 to 2018; and it is Co-integration-tested that there exist long-run equilibrium relationships between annual global mean temperature and average yield (with $\mathrm{P}$ of 0.0000 and t-Statistic of 106.0989) and top yield (with P of 0.0000 and t-Statistic of 221.5318) of world soybean from 1961 to 2018. Thus, taking annual global mean temperature as independent $(X)$ while world soybean yield as dependent $(Y)$, the effect of global warming on the yields from 1961 to 2018 is regression-modelled with constant and respectively shown as in formula (2) of the average and formula (3) of the top. 


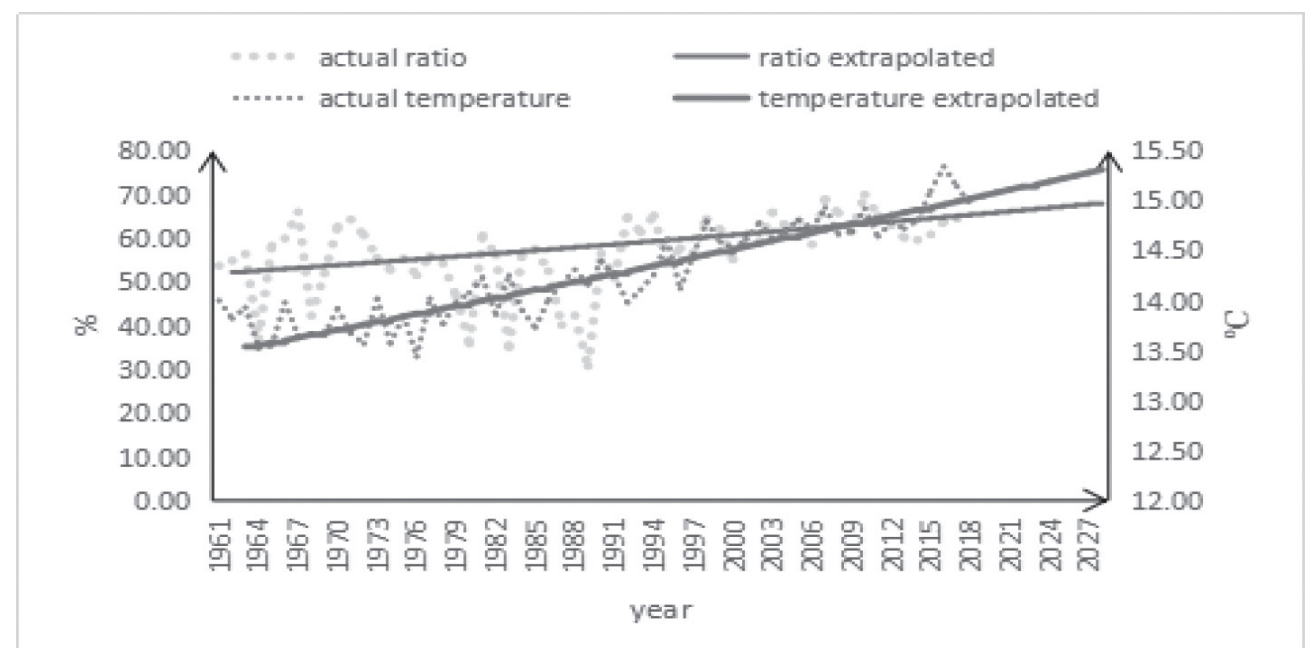

Fig. 3: Global mean temperature $\left({ }^{\circ} \mathrm{C}\right)$ and ratio $(\%)$ of average to top of world soybean yields in 1961 to 2028

Table 5: Equations of five basic models for fitting annual global mean temp from 2009-18

\begin{tabular}{|l|l|}
\hline Model & Equation \\
\hline ARMA $(1,2)$ & $\ln$ tem $_{t}=0.001877+0.651947 \ln$ tem $_{t-1}+0.348053 \ln$ tem $_{t-2}+\varepsilon_{t}-0.662542 \varepsilon_{t-1}-0.337366 \varepsilon_{t-2}$ \\
ARMA $(1,1)$ & $\ln$ tem $_{t}=0.001904+1.029719 \ln$ tem $_{t-1}-0.029719 \ln$ tem $_{t-2}+\varepsilon_{t}-0.981233 \varepsilon_{t-1}$ \\
AR (1) & $\ln$ tem $_{t}=0.001410+0.490169 \ln$ tem $_{t-1}+0.509830 \ln$ tem $_{t-2}+\varepsilon_{t}$ \\
MA (2) & $\ln$ tem $_{t}=0.001864+\varepsilon_{t}-0.896691 \varepsilon_{t-1}-0.088644 \varepsilon_{t-2}$ \\
MA (1) & $\ln$ tem $_{t}=0.001861+\varepsilon_{t}-0.985206 \varepsilon_{t-1}$ \\
\hline
\end{tabular}

Note: 'tem' stands for 'annual global mean temperature'.

Table 6: Regression result of ARIMA (1,0,1) model for annual global mean temp in 2019-28

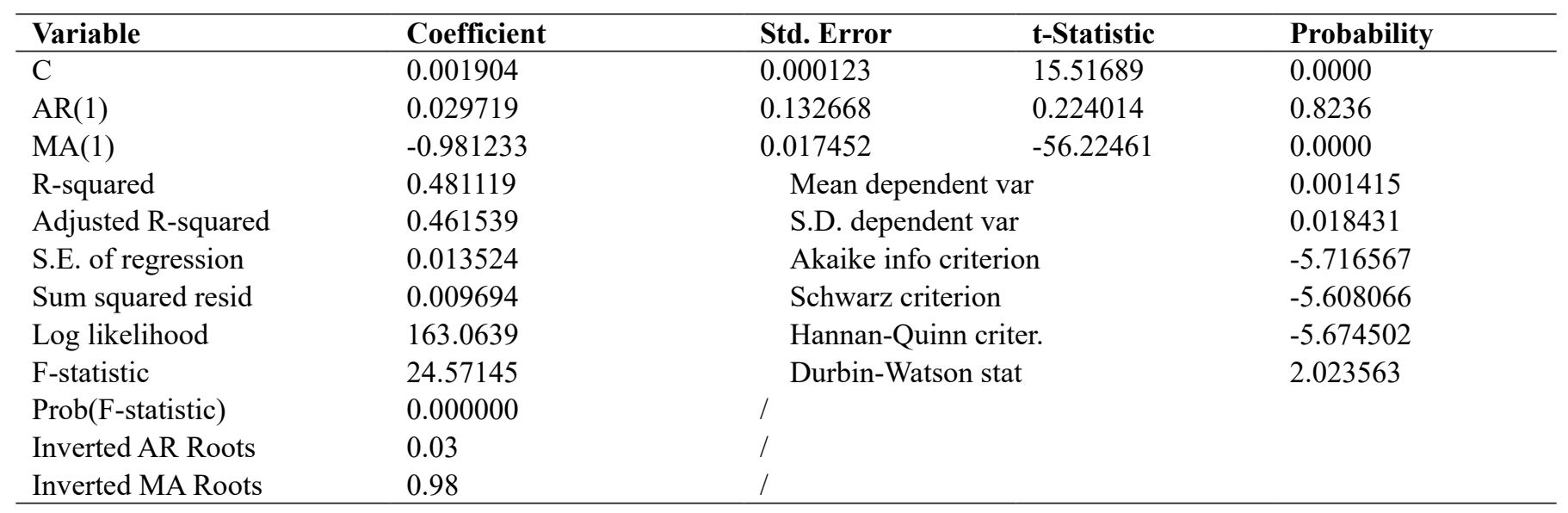

$Y=18168.299-3133.183 X+139.705 X^{2}$

For formula (2), $\mathrm{R}$ squared $=0.819$ while $\mathrm{F}=124.851$ and Sig. $=0.000$.

As shown in formula (2), global warming exerts statistically significant positive impact (at 0.01 level) on average yield of world soybean from 1961 to 2018 with Quadratic function best simulated having one of two highest $\mathrm{R}$ squared values in comparison with Linear of 0.815, Logarithmic of 0.813, Inverse of 0.810, Cubic of 0.819 , Compound of 0.766 , Power of 0.766 , S of 0.765 , Growth of 0.766, Exponential of 0.766 and Logistic of 0.766, and higher F value than the Cubic with 124.739. 
Vol. 23, No. 4

$Y=K /[1+\operatorname{Exp}(12.595-63.805 X)]$

For formula (3), $\mathrm{R}$ squared $=0.414$ while $\mathrm{F}=39.607$ and Sig. $=0.000$.

As shown in formula (3), global warming exerts statistically significant negative impact (at 0.01 level) on top yield of world soybean from 1961 to 2018 having $\mathrm{S}$ function best simulated with higher $\mathrm{R}$ squared value than Linear with 0.378 , Logarithmic with 0.380 , Inverse with 0.382, Quadratic with 0.394, Cubic with 0.394, Compound with 0.409, Power with 0.412, Growth with 0.409, Exponential with 0.409 and Logistic with 0.409.

To see further global warming effects on the yields of world soybean in 1961 to 2028, stationary logarithmic series of annual global mean temperature (in ADF unit root test t-statistic value $=-6.996297$ while critical value $=-4.127338$ at $1 \%$ level) and ARMA $(1,1)$ basic model with the lowest ME of $-0.08 \%$ between fitted values and actual temperatures from 2009 to 2018 among five kinds shown in Table 5, have been used for ARIMA $(1,0,1)$ modelling (table 6$)$ to project the futures by 2028 .

As shown in Table 6, absolute values of both inverted AR root (0.03) and inverted MA root (0.98) have been all below 1.00, showing the ARIMA $(1,0,1)$ model stationary. Annual global mean temperatures in 2019 to 2028 have been projected to be from 15.05 increasingly to $15.31^{\circ} \mathrm{C}$. For example, annual global mean temperature in 2018 projected using the ARIMA $(1,0,2)$ model based on the temperatures from 1961 to 2017 , is $15.12^{\circ} \mathrm{C}$ and only $1.07 \%$ higher than actual one. Then regression model with constant has been used for simulating the dependence of world soybean yields on annual global mean temperature in 1961 to 2028, which reveals that global warming exerts more positive effect on the average yield with Power function (having b1 coefficient of 8.309 and $\mathrm{R}$ squared of 1.000) than that on the top yield with Power function (coefficient $\mathrm{b} 1=6.188$ while $\mathrm{R}$ squared $=1.000$ ). The result was consistent with the scenario from 1961 to 2018 in terms of trend narrowing the gap between average and top of world soybean yields.

\section{Comparison between actual and simulated yields of world soybean}

As shown in figure 2: actual average yields of world soybean increased with slight fluctuation from 1961 to 2018 while average yield extrapolated rises in a curve trend in 1961 to 2028; actual top yields of world soybean fluctuated in rise from 1961 to 2018 while top yield extrapolated rises in a curve trend in 1961 to 2028.

Global mean temperature and ratio between average and top of world soybean yields in 1961 to 2028

As previously mentioned, the 'top yield' can be considered potential limit of the 'average yield' because in a long run the latter will 'chase after' but never meet the former. Though 'average yield' rises generally faster but especially slower than 'top yield'.

According to the projections, average yields of world soybean in 2019, 2020, 2021, 2022, 2023, 2024, 2025, 2026, 2027 and 2028 are 65.70, 65.99, 66.25, 66.51, $66.79,67.05,67.33,67.60,67.86$ and 68.15 per cent of the top ones, respectively. The gap between these two kinds of world soybean yields slowly narrows because the average generally rises at higher rate than the top yields.

As shown in Fig. 3, actual annual global mean temperatures rose in fluctuation from 1961 to 2018 while the extrapolated temperature rises in a linear trend in 1961 to 2028 , so did actual ratio of average to top of world soybean yields and so does the extrapolated ratio; from 1961 to 2018 and 2028 the ratio of average to top of world soybean yields was between 30 and 70 per cent (from the maximum of $69.23 \%$ in 2010 to the minimum of $30.75 \%$ in 1989) and shown a slightly increasing trend in fluctuation, which implies that by 2028 the average yield will increasingly chase after the top yield as it rises faster than the latter, partly due to more positive effect of global warming on the average than that on the top yield in 1961 to 2028 according to their values of coefficient b1 in Power function. As global warming exerts positive effect on average yields while negative on top yields of world soybean or more positive effect on the average than that on the top yields, the opportunities for improving production should be dependent on both high and lowyielding countries.

\section{CONCLUSIONS}

The models based on production function are better applicable to microscopic and static scenario in which the smaller the coverage is, the more precise the estimation will be. In a long run like a population increase in ecosystem, any crop's yield over time theoretically shows a trend of $S$-shaped curve, where the crop's yield is positively accelerated before the turn-point, while 
negatively accelerated after that until the acceleration stopped eventually. For the crop whose current average yield is in low place before the turn-point of such $S$-shaped curve (e.g. below $30 \%$ of potential limit), the opportunities for improving global production should be mainly dependent on raising the crop yield potential in high-yield countries with high efficiency; while for those in high place after the turn-point of such $S$-shaped curve (e.g. above $70 \%$ of potential limit) the opportunities should be mainly dependent on low-yield countries through the amelioration of arable land with high input and output, and for those in middle place around the turnpoint of such $S$-shaped curve (e.g. between 30 and $70 \%$ of potential limit) the opportunities should be dependent on both high and low-yielding countries with integrated efficiency.

\section{ACKNOWLEDGEMENT}

We appreciate the support provided by Climate Change Special Fund of China Meteorological Bureau (CCSF201939) for proposed study.

Conflict of Interest Statement: The author(s) declare(s) that there is no conflict of interest.

Disclaimer: The contents, opinions, and views expressed in the research article published in the Journal of Agrometeorology are the views of the authors and do not necessarily reflect the views of the organizations they belong to.

Publisher's Note: The periodical remains neutral with regard to jurisdictional claims in published maps and institutional affiliations.

\section{REFERENCES}

Aparecido, L.E.D., Torsoni G.B., de Moraes, J.R.D.C., de Meneses, K.C., Lorencone and J.A., Lorencone, P.A. (2020). Modeling the impact of agrometeorological variables on soybean yield in the Mato Grosso Do Sul: 2000-2019. Environ. Devel. Sustain., 23: 5151-5164.

Fuzzo, D.F.S., Carlson, T.N., Kourgialas, N.N. and Petropoulos GP. (2020). Coupling remote sensing with a water balance model for soybean yield predictions over large areas. Earth Sci. Informat., 13(2): 345-359.

Jensen, L. (1990). Guidelines for the application of ARIMA models in time series. Res. Nursing \& Health, 13(6): 429-435.

Petry, M.T., Basso, L.J., Carlesso, R., Armoa, M.S. and Henkes, J.R. (2020). Modeling yield, soil water balance and economic return of soybean under different water deficit levels. Engen. Agricol, 40(4): 526-535.

Rebilas, K, Klimek-Kopyra, A, Bacior M and Zajac T. (2020). A model for the yield losses estimation in an early soybean (Glycine max (L.) Merr.) cultivar depending on the cutting height at harvest. Field Crops Res., 254. https://doi. org/10.1016/j.fcr.2020.107846

Singh, R., Singh, D., Chander Shekhar and Mani, J.K. (2010). Evaluation of 'SOYGRO' model for soybean crop under Hisar conditions. $J$. Agrometeorol., 12(1):121-122.

Stepanov, A.S., Makogonov, S.V. and Tolpin, V.A. (2019). Assessment of soybean yield in the Far East using regression models based on remote sensing data. Sovremennye problemy distantsionnogo zondirovaniya Zemli iz kosmosa, 16 (6): 194-198.

Tovjanin, M.J., Djurdjevic, V., Pejic, B., Novkovic, N., Mutavdzic, B., Markovic, M. and Mackic, K. (2019). Modeling the impact of climate change on yield, water requirements, and water use efficiency of maize and soybean grown under moderate continental climate in the Pannonian lowland. Quarterly Journal of the Hungarian Meteorological Service, IDOJARAS, 123(4): 469-486.

Walikar, L.D., Bhan, M., Giri, A.K., Dubey, A.K. and Agrawal K.K. (2018). Impact of projected climate on yield of soybean using CROPGRO-Soybean model in Madhya Pradesh. J. Agrometeorol., 20(3): 211-215. 